\title{
The analgesic effect of the ultrasound-guided transverse abdominis plane block after laparoscopic cholecystectomy
}

\author{
Yoon Suk Ra, Chi Hyo Kim, Guie Yong Lee, and Jong In Han \\ Department of Anesthesiology and Pain Medicine, School of Medicine, Ewha Womans University, Seoul, Korea
}

Background: Several methods are performed to control the pain after a laparoscopic cholecystectomy. Recently, the transverse abdominis plane block has been proposed to compensate for the problems developed by preexisting methods. This study was designed to evaluate the effect of the ultrasound-guided transverse abdominis plane block (US-TAP block) and compare efficacy according to the concentration of local analgesics in patients undergoing laparoscopic cholecystectomy.

Methods: Fifty-four patients undergoing laparoscopic cholecystectomy were randomized into three groups. The patients in Group Control did not receive the US-TAP block. The patients in Group $\mathrm{B}_{0.25}$ and Group $\mathrm{B}_{0.5}$ received the US-TAP block with $0.25 \%$ and $0.5 \%$ levobupivacaine $30 \mathrm{ml}$ respectively. After the general anesthesia, a bilateral USTAP block was performed using an in-plane technique with $15 \mathrm{ml}$ levobupivacaine on each side. Intraoperative use of remifentanil and postoperative demand of rescue analgesics in PACU were recorded. The postoperative verbal numerical rating scale (VNRS) was evaluated at 20, 30, and $60 \mathrm{~min}$, and 6, 12, and $24 \mathrm{hr}$. Postoperative complications, including pneumoperitoneum, bleeding, infection, and sleep disturbance, were also checked.

Results: The intraoperative use of remifentanil, postoperative VNRS and the postoperative demand of rescue analgesics were lower in the groups receiving the US-TAP block (Group $\mathrm{B}_{0.25}$ and Group $\mathrm{B}_{0.5}$ ) than Group Control. There were no statistically or clinically significant differences between Group $\mathrm{B}_{0.25}$ and Group $\mathrm{B}_{0.5}$. No complications related to the US-TAP block were observed.

Conclusions: The US-TAP block with $0.25 \%$ or $0.5 \%$ levobupivacaine $30 \mathrm{ml}$ ( $15 \mathrm{ml}$ on each side) significantly reduced postoperative pain in patients undergoing laparoscopic cholecystectomy. (Korean J Anesthesiol 2010; 58: 362-368)

Key Words: Laparoscopic cholecystectomy, Levobupivacaine, Postoperative pain, Transverse abdominis plane block, Ultrasound.

Received: December 16, 2009. Revised: 1st, December 24, 2009; 2nd, January 12, 2010. Accepted: February 23, 2010.

Corresponding author: Chi Hyo Kim, M.D., Department of Anesthesiology and Pain Medicine, School of Medicine, Ewha Womans University, 911-1, Mok-dong, Yangcheon-gu, Seoul 158-710, Korea. Tel: 82-2-2650-5560, Fax: 82-2-2655-2924, E-mail: 120060@mm.ewha.ac.kr

This paper is a Master's thesis.

(ㄷ) This is an open-access article distributed under the terms of the Creative Commons Attribution Non-Commercial License (http:// creativecommons.org/licenses/by-nc/3.0/), which permits unrestricted non-commercial use, distribution, and reproduction in any medium, provided the original work is properly cited. 


\section{Introduction}

Although laparoscopic cholecystectomy, a widely performed surgery, is known for less pain compared to that of laparotomy, many patients actually complain of considerable pain after the operation $[1,2]$.

Intravenous patient-controlled analgesia (IV-PCA), patientcontrolled thoracic epidural analgesia, intraperitoneal injection of local anesthetics, low-pressure pneumoperitoneum, and warmed air supply have been used for pain control after laparoscopic cholecystectomy [1,3]. IV-PCA, while useful, has the side effects of opioids [4]. Though the analgesic effect of patient-controlled thoracic epidural analgesia is better than that of IV-PCA [5], there is a potential risk of dural puncture, infection, and epidural hematoma, as well as muscle weakness, which may cause even paralysis of respiratory muscles $[6,7]$. An intraperitoneal injection of local anesthetics also has the problems of insufficient pain control and short duration of analgesia $[8,9]$.

In order to complement the problems of such analgesic methods and reduce the pain sufficiently, a peripheral nerve block can be used as an alternative method. Firstly described by Rafi [10], the transverse abdominis plane block (TAP block) enables pain control through blocking sensory nerves by injecting local anesthetics into the neurofascial plane in the abdominal muscle.

The conventional TAP block is performed at the so-called "triangle of Petit", which is bounded posteriorly by the lattisimus dorsi muscle, anteriorly by the external oblique muscle (EOM), inferiorly by the iliac crest [11], by advancing the needle for a "pop" or "double pop", the sensation of puncturing fascia, to inject the local anesthetics, without knowing the inner structure of the abdominal cavity and the injection site [12-14]. However, this blind technique may cause an inappropriate block since the location of the needle may not be precise [15]. Fatal complications, such as large bowl puncture and liver injury, have been also reported $[16,17]$. Recently, complications are able to be minimized by performing an ultrasound-guided transverse abdominis plane block (US-TAP block), since precise location of the needle and diffusion of local anesthetics can be directly observed by this technique $[18,19]$.

In this study, we have compared the analgesic effect of levobupivacaine concentration after a laparoscopic cholecystectomy by performing a US-TAP block with $0.25 \%$ and $0.5 \%$ of levobupivacaine, $15 \mathrm{ml}$ each for the left and the right, at a total of $30 \mathrm{ml}$, on the patients for whom the operation was performed under general anesthesia.

\section{Materials and Methods}

This study was conducted with 54 ASA physical status I-II male and female adult patients between the ages of 20-65 who were scheduled to undergo laparoscopic cholecystectomy under general anesthesia. In addition, the study was performed after approval was obtained from the Hospital Ethics Committee and written informed consent from the patients with an explanation regarding the purpose, methods, effects, and complications. Patients were excluded if there was a history of relevant local anesthetics allergy or opioids addiction, or if they had coagulation disorder or there was infection at the needle insertion site. Patients were randomly allocated into three groups: one group to undergo general anesthesia but not perform the US-TAP block (Group Control, $\mathrm{n}=18$ ), another to undergo $0.25 \%$ levobupivacaine injection, $15 \mathrm{ml}$ each at the left and the right, at a total of $30 \mathrm{ml}$ (Group $\mathrm{B}_{0.25}, \mathrm{n}=18$ ) and the other to $0.5 \%$ levobupivacaine injection, $15 \mathrm{ml}$ each at the left and the right, at a total of $30 \mathrm{ml}$ (Group $\mathrm{B}_{0.5}, \mathrm{n}=18$ ). By means of the preliminary clinical study, the sample size was calculated so that reduction of VNRS 3 or more would be statistically significant with the significance level, $\alpha$, of 0.05 and the power of test, $1-\beta$, of $80 \%$. We calculated that 14.29 patients would be required per group, and elected 18 patients per group, considering the patients that might be excluded.

Premedication was not performed. Noninvasive blood pressure cuff, electrocardiograph, pulse oximetry, and bispectoral index (BIS) were attached to the patients after arriving in the operating room. Induction of general anesthesia was performed by injecting glycopyrolate $0.2 \mathrm{mg}$ and midazolam $0.05 \mathrm{mg} / \mathrm{kg}$ and introducing $2 \%$ propofol (Fresofol ${ }^{\circledR}$, Fresenius Kabi, Korea Ltd, Korea) and remifentanil (Ultiva ${ }^{\circledR}$, GlaxoSmithKlien, UK), which was diluted to $50 \mu \mathrm{g} / \mathrm{ml}$ with a Target Controlled Infusion (TCI, Orchestra $^{\circledR}$, Fresenius vial, France) until effective concentration became $3.0 \mu \mathrm{g} / \mathrm{ml}$ and $2.5 \mathrm{ng} / \mathrm{ml}$. After unconsciousness, rocuronium $0.6 \mathrm{mg} / \mathrm{kg}$ was injected and then endotracheal intubation was performed following the 90 seconds of mask ventilation. Controlled ventilation was done by providing oxygen and nitrous oxide at the flow rate of $2 \mathrm{~L}$ per min each. Maintaining the effective concentration of propofol at $2 \mu \mathrm{g} /$ $\mathrm{ml}$, the blood pressure was regulated in the $20 \%$ range of the blood pressure measured when entering the operation room by regulating the concentration of remifentanil. In addition, the BIS was maintained within the range of 40 to 60 and the endtidal carbon dioxide partial pressure within the range of 35 to 40 $\mathrm{mmHg}$.

When the vital signs were stabilized after endotracheal intubation, the TAP block was performed through ultrasound (SonoSite M-Turbo ${ }^{\circledR}$, Sonosite, USA) guided method. After drapping the abdominal part between the 12th rib bone and iliac crest with umbilicus at the center, the "Petit triangle" was palpated (Fig. 1). The sterilized gel were sufficiently coated on the linear probe (HPL38x, 6-13 MHz, Sonosite, USA). External 


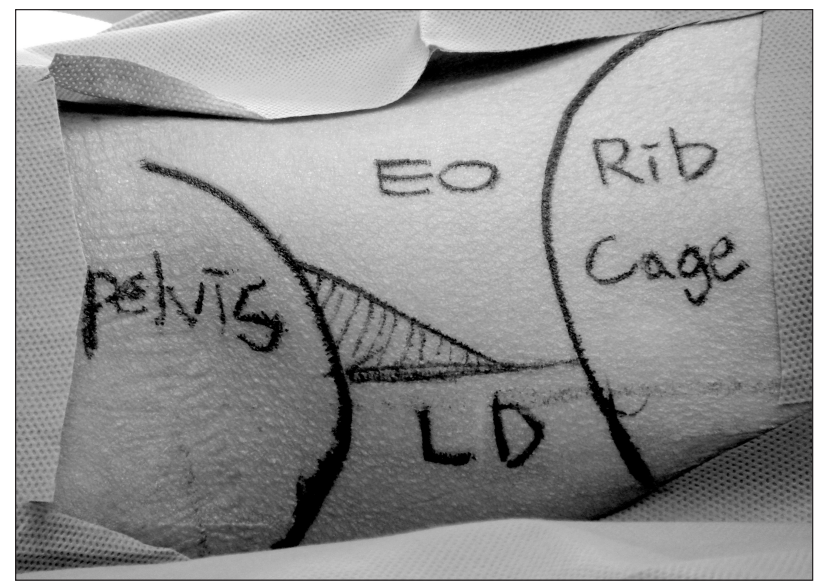

Fig. 1. Surface anatomy of the 'Petit' triangle. LD: lattisimus dorsi muscle, EO: external oblique muscle.

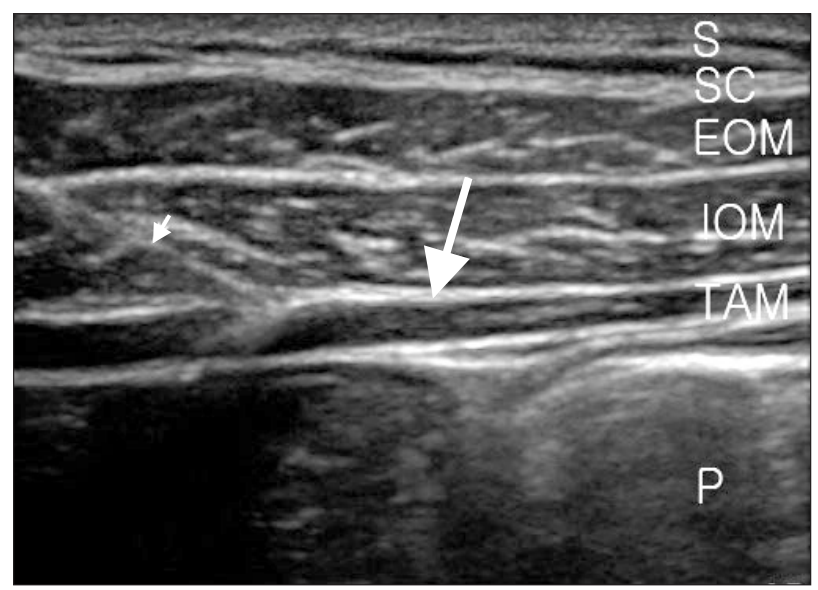

Fig. 2. Ultrasound view of abdominal muscle and fascia during needle insertion. Arrow point to transverse abdominis plane. Small arrow point to needle. S: skin, SC: subcutaneous tissue, EOM: external oblique muscle, IOM: internal oblique muscle, TAM: transverse abdominis muscle, P: peritonial cavity.

oblique muscle (EAO), internal oblique muscle (IOM), transverse abdominis muscle (TAM), and their fascia at the boundaries were identified beneath the skin, subcutaneous tissue. A 22 G needle (Stimuplex ${ }^{\circledR}$ A, B. Braun, Germany) of 50 $\mathrm{mm}$ length was advanced by an ultrasound guided in-plane technique at the anterior axillary line. The resistance as the needle tip reached the EOM, the first "pop" sensation as the needle entered the plane between the EOM and IOM fascial layer, and second "pop" sensation as the needle entered the plane between IOM and TAM fascial layer were followed in order, and the exact location of the needle tip was checked by ultrasound (Fig. 2). After checking the exact location of the needle tip, $1 \mathrm{ml}$ each of $0.25 \%$ and $0.5 \%$ levobupivacaine were injected for Group $\mathrm{B}_{0.25}$ and Group $\mathrm{B}_{0.5}$, respectively, and the

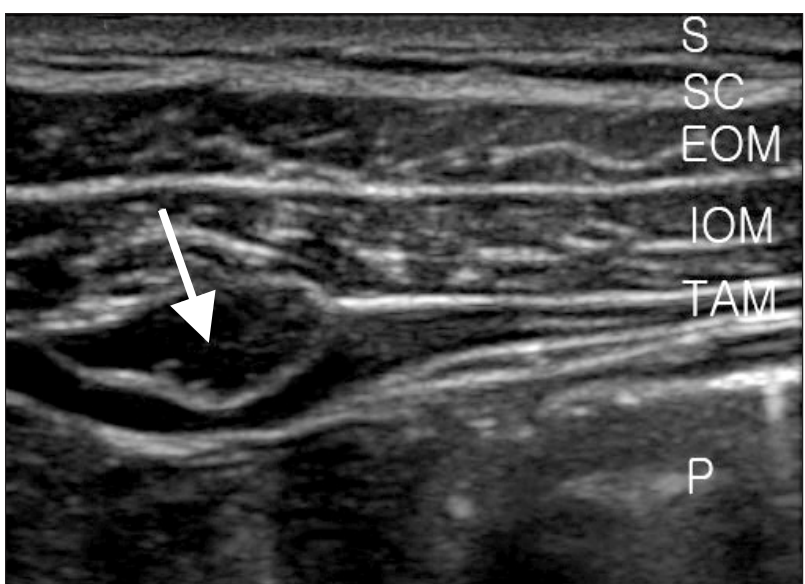

Fig. 3. Ultrasound view of abdominal muscle and fascia after $1 \mathrm{ml}$ injection of local anesthetics. Arrow point to transverse abdominis plane. S: skin, SC: subcutaneous tissue, EOM: external oblique muscle, IOM: internal oblique muscle, TAM: transverse abdominis muscle, P: peritonial cavity.

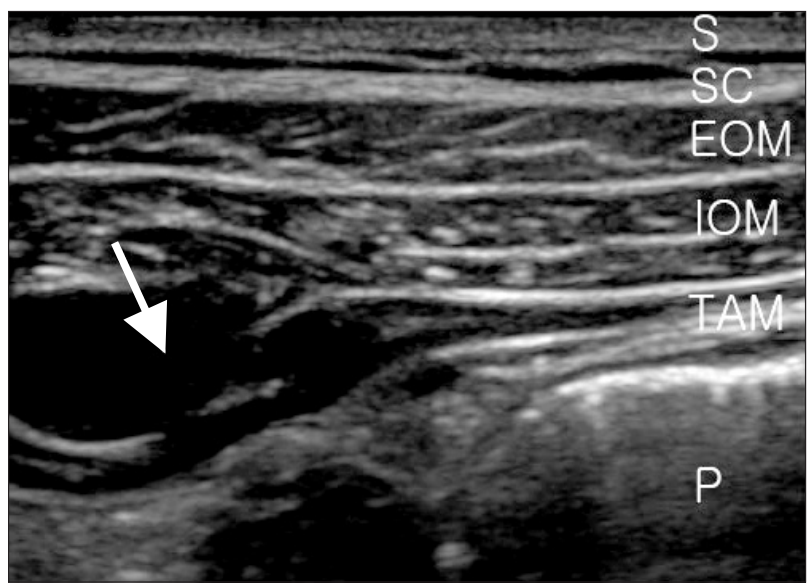

Fig. 4. Ultrasound view of abdominal muscle and fascia after total $15 \mathrm{ml}$ injection of local anesthetics. Arrow point to transverse abdominis plane. S: skin, SC: subcutaneous tissue, EOM: external oblique muscle, IOM: internal oblique muscle, TAM: transverse abdominis muscle, P: peritonial cavity.

diffusion of local anesthetics between fascial layer between the IOM and TAM was confirmed (Fig. 3). Next, the injection of the remaining $14 \mathrm{ml}$ followed (Fig. 4). The amount of $15 \mathrm{ml}$ was also injected in the opposite side using the identical technique. The US-TAP block was performed by one skilled anesthesiologist.

The total dose of remifentanil injected during the entire operation was recorded. The pain score was assessed by a doctor who was blinded to the group allocation using the verbal numerical rating scale (VNRS: $0=$ no pain, $10=$ the severest pain imaginable) at $20 \mathrm{~min}, 30 \mathrm{~min}$, and $60 \mathrm{~min}$ after the patient was moved to recovery room and at $6 \mathrm{hr}, 12 \mathrm{hr}$, and $24 \mathrm{hr}$ after the end of the operation. When the VNRS was higher than 6 and the 
patient wanted an analgesics in the recovery room, ketorolac $30 \mathrm{mg}$ was injected. If the pain was not relieved, fentanyl $20 \mu \mathrm{g}$ was further injected. In addition, for the purpose of pain control in the ward, ketorolac $30 \mathrm{mg}$ was injected into all the patients 3 times during postoperative 24 hours for 8 hour intervals by the surgeons. The patients were visited 24 hours after the operation and asked about the sleep disturbance due to pain at the operation site. The occurrence of complications, such as pneumoperitoneum due to intestinal puncture, bleeding, and infection, was also assessed.

All the measurement data were presented as mean \pm standard deviation, and the statistical processing was performed using SPSS (Ver 16.0), analyzing VNRS and comparing the group difference of the total dose of remifentanil used during the operation using one-way ANOVA. The categorical data were presented as the number of patients and analyzed using chisquare analysis or Fisher's exact test. The data with $\mathrm{P}<0.05$ was considered as statistically significant.

Table 1. Patient Characteristics

\begin{tabular}{lccc}
\hline \multicolumn{1}{c}{ Group } & $\begin{array}{c}\text { Control } \\
(\mathrm{n}=18)\end{array}$ & $\begin{array}{c}\mathrm{B}_{0.25} \\
(\mathrm{n}=18)\end{array}$ & $\begin{array}{c}\mathrm{B}_{0.5} \\
(\mathrm{n}=18)\end{array}$ \\
\hline Age $(\mathrm{yr})$ & $43.4 \pm 12.4$ & $48.2 \pm 10.7$ & $45.0 \pm 11.1$ \\
Weight $(\mathrm{kg})$ & $63.6 \pm 9.2$ & $66.2 \pm 9.6$ & $61.8 \pm 10.0$ \\
Height $(\mathrm{cm})$ & $163.6 \pm 6.9$ & $159.7 \pm 16.6$ & $161.6 \pm 7.7$ \\
BMI $\left(\mathrm{kg} / \mathrm{m}^{2}\right)$ & $23.6 \pm 3.4$ & $24.7 \pm 3.3$ & $23.5 \pm 2.9$ \\
Sex (Male/Female) & $8 / 10$ & $11 / 7$ & $9 / 9$ \\
ASA physical status $(1 / 2)$ & $11 / 7$ & $10 / 8$ & $12 / 6$ \\
History of & & & \\
$\quad$ Hypertension & 5 & 6 & 3 \\
$\quad$ Diabetes mellitus & 3 & 1 & 1 \\
$\quad$ Abdominal surgery & 6 & 6 & 5 \\
Operation time (min) & $81.1 \pm 26.5$ & $89.7 \pm 22.7$ & $89.7 \pm 31.8$ \\
\hline
\end{tabular}

Results are expressed as mean \pm SD or numbers of patients. Group $\mathrm{B}_{0.25}$ received the ultrasound-guided transverse abdominis plane block bilaterally with $0.25 \%$ levobupivacaine $30 \mathrm{ml}$. Group $\mathrm{B}_{0.5}$ received the ultrasound-guided transverse abdominis plane block bilaterally with $0.5 \%$ levobupivacaine $30 \mathrm{ml}$.

\section{Results}

With 18 patients per group, a total of 54 patients were entered into the study. There was no statistically significant difference among the three groups in terms of age, weight, height, BMI, sex, ASA physical status, history of hypertension, history of diabetes mellitus, history of abdominal surgery, and operation time (Table 1).

The VNRS of Group $\mathrm{B}_{0.25}$ and Group $\mathrm{B}_{0.5}$ was assessed at 20 min, $30 \mathrm{~min}, 60 \mathrm{~min}, 6 \mathrm{hr}, 12 \mathrm{hr}$, and $24 \mathrm{hr}$ after the operation was significantly lower than that of the Group Control $(\mathrm{P}<0.001$, Table 2), but there was no significant difference between Group $\mathrm{B}_{0.25}$ and Group $\mathrm{B}_{0.5}$ (Table 2).

The remifentanil use for Group $\mathrm{B}_{0.25}$ and Group $\mathrm{B}_{0.5}$ during the operation was significantly lower than that for the Group Control ( $\mathrm{P}<0.001$, Table 3 ), but there was no significant difference between Group $\mathrm{B}_{0.25}$ and Group $\mathrm{B}_{0.5}$ (Table 3).

The number of patients whom ketorolac was injected in the recovery room after the operation was 17,4 , and 4 from the Group Control, Group $\mathrm{B}_{0.25}$, and Group $\mathrm{B}_{0.5}$, respectively, which was significantly lower for the Group $B_{0.25}$ and Group $B_{0.5}$ than that of the Group Control $(\mathrm{P}<0.001$, Table 3$)$. The number of

Table 2. Verbal Numerical Rating Scale (VNRS)

\begin{tabular}{lccc}
\hline \multicolumn{1}{c}{ Group } & $\begin{array}{c}\text { Control } \\
(\mathrm{n}=18)\end{array}$ & $\begin{array}{c}\mathrm{B}_{0.25} \\
(\mathrm{n}=18)\end{array}$ & $\begin{array}{c}\mathrm{B}_{0.5} \\
(\mathrm{n}=18)\end{array}$ \\
\hline VNRS at 20 min after operation & $8.6 \pm 1.76$ & $3.3 \pm 1.84^{*}$ & $3.2 \pm 1.89^{*}$ \\
VNRS at 30 min after operation & $8.2 \pm 1.72$ & $2.9 \pm 1.68^{*}$ & $2.8 \pm 1.38^{*}$ \\
VNRS at 60 min after operation & $6.9 \pm 1.57$ & $2.8 \pm 1.70^{*}$ & $2.6 \pm 1.46^{*}$ \\
VNRS at 6 h after operation & $6.1 \pm 1.98$ & $3.1 \pm 1.55^{*}$ & $1.9 \pm 1.43^{*}$ \\
VNRS at 12 h after operation & $5.1 \pm 2.01$ & $2.1 \pm 1.41^{*}$ & $1.8 \pm 1.16^{*}$ \\
VNRS at 24 h after operation & $4.4 \pm 1.68$ & $1.6 \pm 1.46^{*}$ & $1.3 \pm 0.97^{*}$
\end{tabular}

Results are expressed as mean \pm SD. Group $\mathrm{B}_{0.25}$ received the ultrasound-guided transverse abdominis plane block bilaterally with $0.25 \%$ levobupivacaine $30 \mathrm{ml}$. Group $\mathrm{B}_{0.5}$ received the ultrasoundguided transverse abdominis plane block bilaterally with $0.5 \%$ levobupivacaine $30 \mathrm{ml}$. *P value $<0.001$ compared as Group Control.

Table 3. Analgesic Requirement, Complications and Sleep Disturbance

\begin{tabular}{|c|c|c|c|}
\hline Group & $\begin{array}{l}\text { Control } \\
(\mathrm{n}=18)\end{array}$ & $\begin{array}{c}\mathrm{B}_{0.25} \\
(\mathrm{n}=18)\end{array}$ & $\begin{array}{c}\mathrm{B}_{0.5} \\
(\mathrm{n}=18)\end{array}$ \\
\hline Total intraoperative remifentanil $(\mu \mathrm{g})$ & $685.5 \pm 200.0$ & $469.8 \pm 137.1^{*}$ & $435.1 \pm 117.6^{*}$ \\
\hline Intraoperative remifentanil $(\mu \mathrm{g} / \mathrm{min} / \mathrm{kg})$ & $0.09 \pm 0.03$ & $0.05 \pm 0.01^{*}$ & $0.05 \pm 0.02 *$ \\
\hline \multicolumn{4}{|l|}{ Analgesics in PACU } \\
\hline Ketorolac $30 \mathrm{mg}$ IV & 17 & $4^{*}$ & $4^{*}$ \\
\hline Fentanyl $20 \mu \mathrm{g}$ IV & 4 & $0^{\dagger}$ & $0^{\dagger}$ \\
\hline $\begin{array}{l}\text { Complications } \\
\text { (pneumoperitonem/bleeding/infection) }\end{array}$ & 0 & 0 & 0 \\
\hline Sleep disturbance & 6 & 2 & $0^{\dagger}$ \\
\hline
\end{tabular}

Results are expressed as mean \pm SD or numbers of patients. Group $\mathrm{B}_{0.25}$ received the ultrasound-guided transverse abdominis plane block bilaterally with $0.25 \%$ levobupivacaine $30 \mathrm{ml}$. Group $\mathrm{B}_{0.5}$ received the ultrasound-guided transverse abdominis plane block bilaterally with $0.5 \%$ levobupivacaine $30 \mathrm{ml}$. *P value $<0.001$ compared as Group Control. ${ }^{\dagger} \mathrm{P}$ value $<0.05$ compared as Group Control. 
patients whom fentanyl was injected in the recovery room was 4, 0 , and 0 from the Group Control, Group $\mathrm{B}_{0.25}$, and Group $\mathrm{B}_{0.5}$, respectively, which was significantly lower for the Group $B_{0.25}$ and Group $\mathrm{B}_{0.5}$ than that of the Group Control ( $\mathrm{P}<0.05$, Table 3). There was no significant difference between Group $B_{0.25}$ and Group $\mathrm{B}_{0.5}$ (Table 3).

There was no case of complications, such as pneumoperitoneum due to intestinal puncture, bleeding, or infection among the 36 patients who underwent the US-TAP block. The number of patients who complained of sleep disturbance caused by pain at operation site was 6, 2, and 0 from the Group Control, Group $\mathrm{B}_{0.25}$, and Group $\mathrm{B}_{0.5}$, respectively, which was significantly lower in the Group $\mathrm{B}_{0.5}$ than that of the Group Control $(\mathrm{P}<0.05$, Table 3$)$.

\section{Discussion}

In this study, we have compared the analgesic effect by performing the US-TAP block through injecting $0.25 \%$ and $0.5 \%$ of levobupivacaine, $15 \mathrm{ml}$ each for the left and the right, at a total of $30 \mathrm{ml}$, after a laparoscopic cholecystectomy under general anesthesia. Both the Group $\mathrm{B}_{0.25}$ and Group $\mathrm{B}_{0.5}$ that underwent the US-TAP block showed a significantly lower VNRS than that of the Group Control, as assessed at $20 \mathrm{~min}, 30 \mathrm{~min}, 60$ min, $6 \mathrm{hr}, 12 \mathrm{hr}$, and $24 \mathrm{hr}$ after the operation. The total dose of remifentanil used during the operation and the amount of analgesics used in the recovery room after the operation were also remarkably lower in the Group $\mathrm{B}_{0.25}$ and Group $\mathrm{B}_{0.5}$ than the Group Control, indicating that the US-TAP block had a good analgesic effect after laparoscopic cholecystectomy until 24 hours. The result of no significant difference between the Group $\mathrm{B}_{0.25}$ and Group $\mathrm{B}_{0.5}$ showed that $0.25 \%$ levobupivacaine $30 \mathrm{ml}$ can have a sufficient analgesic effect.

"Pop" technique is applied not only in the TAP block but also in ilioinguinal nerve and iliohypogastric nerve blocks [20]. However, the procedure, which depends solely on the palpated sensation without a visual guide, can cause intestinal puncture [16], unexpected diffusion of local anesthetics into additional body parts, which may result in subsequent motor nerve paralysis [15], and even severe complication such as liver damage also may happen [17]. Using ultrasound, advancing the needle as the anatomical structure and injecting local anesthetics at the right position can be performed. The precise local anesthetics diffusion range are also checked by ultrasound. Because of that precise procedure, the stability of the procedure can be elevated and the quality of the nerve block can be enhanced. Therefore, we have applied a ultrasound for the TAP block by the in-plane technique, having the linear probe positioned at the Petit triangle, as described by Walter et al. [21]. There was no incidence of complication during the procedure.

The TAP block is simple and the effect lasts long after the operation. It has been proved to be effective for the postoperative analgesia in large bowl surgery [13], laparoscopic operation [22], Cesarean section [14], and retropubic prostatectomy [12], etc. According to the study of O'Donnell [12] and McDonell et al. [14], the TAP block effect lasts for 36 to 48 hours, which might be due to the slow clearance of local anesthetics in the TAP where relatively less blood vessels are located [14]. Moreover, since less blood vessels are located in the TAP, the risk of systemic toxicity from the local anesthetics, which may be caused by blood vessel puncture, the complication that frequently occurs during other peripheral nerve block procedures, can be reduced. The simplicity of the procedure can also provide an advantage for clinical use. The duration of the procedure in this study was approximately $4-5$ minutes, and the Petit triangle, the reference point of ultrasound guide, as well as the muscles, nerves, and fascias, could be easily identified by ultrasound. The procedure was also conducted in a supine position, not changing from the patient's position after general anesthesia.

El-Dawlatly et al. [18] compared the group of patients to which $0.5 \%$ bupivacaine $15 \mathrm{ml}$ was injected at both left and right sides by means of the US-TAP block after general anesthesia to the control group. As a result of the postoperative analgesia by means of IV-PCA, the morphine use for 24 hours after the operation was significantly less in the group of patients who underwent the US-TAP block after general anesthesia than that of the group of patients who underwent general anesthesia only. As a result of the postoperative analgesia by means of IVPCA, the morphine use until 24 hours after the operation was significantly less in the group of patients who underwent the US-TAP block after general anesthesia than that of the group of patients who underwent general anesthesia only. In our study, the US-TAP block was performed at both left and right sides with $0.25 \%$ and $0.5 \%$ levobupivacaine $15 \mathrm{ml}$ for each side, and the pain control was medicated depending on the VNRS and the request of the patients to control the pain, not generally conducting the postoperative analgesia by means of IV-PCA. Although the same conclusion that the US-TAP block has good analgesic effect after a laparoscopic cholecystectomy was derived from both of the studies, our result cannot be compared with that of El-Dawlatly et al. [18], since VNRS was not assessed in their study. Thus, though the US-TAP block can be an effective analgesic method, further research is needed to investigate whether it is more efficient than IV-PCA and what effects can be drawn by the combination method of both of them.

There are a lot of causes that develop the pain after a laparoscopic cholecystectomy. The mechanisms suggested for the 
cause of the pain are the secondary visceral pain due to gall bladder resection, abdominal wall pain due to the abdominal wall extension by the gas injected to the abdominal cavity, and the pain due to the incision at the trocar site [2]. However, it is not yet certain which is the primary cause for the postoperative pain [2]. The cause for the pain could not be distinguished, because the pattern of pain complaints from the patient was obscure in this study. So we were not able to understand the specific origin of the pain that was reduced by the US-TAP block. Thus, an additional study is required with respect to the analgesia mechanism of the US-TAP block.

In the TAP block, a local anesthetics is injected into the T7-T12 intercostal nerve, ilioinguinal nerve, iliohypogastric nerve, and the lateral cutaneous branches of dorsal rami of the L1-L3 at the neurofascial plane between IOM and TAM, in order to block the nerves that dominate the sense of the abdominal cavity $[11,23]$. Regarding the significant sensory blocking range, McDonell et al. [24] reported that it is in between the T7-L1, based on radioactive examination. Tran et al. [25] reported that the dye injected to the TAP was distributed at the T10-L1, based on the cadaver study. In our study, the sensory blocking range was not precisely assessed because the procedure had performed after induction of general anesthesia. Hence, a systematic research regarding the sensory blocking range and the success rate of the procedures, depending on the diffusivity of local anesthetics, must be performed.

The appropriate dose and concentration of injected local anesthetics also needs to be investigated. McDonnell et al. [13] reported that the dose of morphine used during postoperative 24 hours in the patients who underwent the large bowl surgery with the TAP block that was performed with $0.375 \%$ levobupivacaine $20 \mathrm{ml}, 10 \mathrm{ml}$ injected to each side, decreased by $70 \%$. They also reported that the total dose of morphine injected by the IV-PCA to the patients who underwent Cesarean section for 48 hours after the operation was reduced by the TAP block that conducted with $0.75 \%$ ropivacaine $1.5 \mathrm{mg} / \mathrm{kg}$ (Max. $150 \mathrm{mg}$ ), as compared to the total dose of morphine used in the controls [14]. In addition, El-Dawlatly et al. [18] reported that the morphine used for 24 hours after the operation of patients who underwent laparoscopic cholecystectomy was significantly reduced by the US-TAP block conducted with $0.5 \%$ bupivacaine $30 \mathrm{ml}, 15 \mathrm{ml}$ injected in each side. In our study, $0.25 \%$ and $0.5 \%$ levobupivacaine $30 \mathrm{ml}$ was injected in the patients, and it effectively reduced the pain without any complications when compared with that of the control group. The result that there was no significant difference in the effect between the concentrations of $0.25 \%$ and $0.5 \%$ can be a useful reference for clinical applications.

In conclusion, the US-TAP block could reduce the amount of opioids during operation and postoperative analgesics by decreasing the pain for 24 hours after a laparoscopic cholecystectomy. Since the procedure is relatively simple, not causing any complications, it can be utilized as a useful analgesic method during and after the operation. To achieve this, further research is required on the study of pharmacodynamic characteristics in the TAP, sensory blocking range of local anesthetics, a comparison with IV-PCA, and the analgesic mechanisms of the TAP block.

\section{References}

1. Barczynski M, Herman RM. A prospective radomized trial on comparison of low-pressure (LP) and standard-pressure (SP) pneumoperitonium for laparoscopic cholecystctomy. Surg Endosc 2003; 17: 533-8

2. Wills VL, Hunt DR. Pain after laparoscopic cholecystectomy. Br J Surg 2000; 87: 273-84.

3. Mouton WG, Bessell JR, Millard SH, Baxter PS, Maddern GJ. A randomized controlled trial assessing the benefit of humidified insufflation gas during laparoscopic surgery. Surg Endosc 1999; 13: 106-8.

4. Hong D, Flood P, Diaz G. The side effects of morphine and hydromorphone patient - controlled analgesia. Anesth Analg 2008; 107: 1384-9.

5. Erol DD, Yilmaz S, Polat C, Arikan Y. Efficacy of thoracic epidural analgesia for laparoscopic cholecystectomy. Adv Ther 2008; 25: 4552.

6. Katircioglu K, Hasegeil L, Ibrahimhakkioglu HF, Ulusoy B, Damar H. A retrospective of 34,109 epidural anesthetics for obstetric and gynecologic procedures at a single private hospital in Turkey. Anesth Analg 2008; 107: 1742-5.

7. Morgan GE, Mikhail M, Murray MJ. Clinical anesthesiology. 4th ed. New York, McGraw-Hill companies. 2006, pp 316-21.

8. Boddy AP, Mehta S, Rhodes M. The effect of intraperitoneal local anesthesia in laparoscopic cholecystectomy. a systemic review and meta-analysis. Anesth Analg 2006; 103: 682-8.

9. Cunnuffe MG, McAnena OJ, Dar MA, Calleary J, Flynn N. A prospective randomized trial of intraoperative bupivacaine irrigation for management of shoulder-tip pain following laparoscopy. Am J Surg 1998; 176: 258-61.

10. Rafi AN. Abdominal field block: a new approach via the lumbar triangle. Anaesthesia 2001; 56: 1024-6.

11. Netter FH. Abdomen posterolateral abdominal wall. In: Atlas of human anatomy summit. Edited by Netter FH. New Jersey. The Ciba-Geigy Corporation. 1989, pp 231-40.

12. O'Donnell BD, McDonnell JG, McShane AJ. The transversus abdominis plane (TAP) block in open retropubic prostatectomy. Reg Anesth Pain Med 2006; 31: 91.

13. McDonnell JG, O'Donnell B, Curley G, Heffernan A, Power C, Laffey JG. The anlagesic efficacy of transversus abdominis plane block after abdominal surgery: a prospective randomized controlled trial. Anesth Analg 2007; 104: 193-7.

14. McDonnell JG, Curley G, Carney J, Benton A, Costello J, Maharaj $\mathrm{CH}$, et al. The analgesic efficacy of transversus abdominis plane block after cesarean delivery: a randomized controlled trial. Anesth 
Analg 2008; 106: 186-91.

15. Shivashanmugam T, Kundra P, Sudhakar S. Iliac compartment block following ilioinguinal iliohypogastric nerve block. Paediatr Anaesth 2006; 16: 1084-6.

16. Jöhr M, Sossai R. Colonic puncture during ilioinguinal nerve block in a child. Anesth Analg 1999; 88: 1051-2.

17. Farooq M, Carey M. A case of liver trauma with a blunt regional anesthesia needle while performing transversus abdominis plane block. Reg Anesth Pain Med 2008; 33: 274-5.

18. El-Dawlatly AA, Turkistani A, Kettner SC, Machata AM, Delvi $\mathrm{MB}$, Thallaj A, et al. Ultrasound-guided tansversus abdominis plane block: description of a new technique and comparison with conventional systemic analgesia during laparoscopic cholecystectomy. Br J Anaesth 2009; 102: 763-7.

19. Hebbard P. Subcostal transversus abdominis plane block under ultrasound guidance. Anesth Analg 2008; 106: 674-5.
20. Van Schoor AN, Boon JM, Bosenberg AT, Abrahams PH, Meiring JH. Anatomical considerations of the pediatric ilioinguinal/ iliohypogastric nerve block. Paediatr Anaesth 2005; 15: 371-7.

21. Walter EJ, Smith P, Albertyn R, Uncle DR. Ultrasound imaging for transversus abdominis blocks. Anaesthesia 2008; 63: 211.

22. Mukhtar K, Singh S. Transversus abdominis plane block for laparoscopic surgery. Br J Anaesth 2009; 102: 143-4.

23. Netter FH. Back and spinal cord. In: Atlas of human anatomy summit. Edited by Netter FH: New Jersey, The Ciba-Geigy Corporation. 1989, pp 145-55.

24. McDonnell JG, O'Donnell BD, Farrell T, Gough N, Tuite D, Power C, et al. Transversus abdominis plane block: a cadaveric and radiological evaluation. Reg Anesth Pain Med 2007; 32: 399-404.

25. Tran TM, Ivanusic JJ, Hebbard P, Barrington MJ. Determination of spread of injectate after ultrasound-guided transverse abdominis plane block: a cadaveric study. Br J Anaesth 2009; 102: 123-7. 